Original article

\title{
Morphometric parameters of mammary glands in women of different body types in the normal condition and in case of tubular breast deformity
}

\author{
Regina A. Pakhomova ${ }^{1}$, Georgy E. Karapetyan ${ }^{1}$, Lyudmila V. Kochetova ${ }^{1}$, Lyudmila V. Sindeeva ${ }^{1}$, \\ Natalya A. Karelina ${ }^{1}$, Nikolay A. Ratushny ${ }^{2}$ \\ ${ }^{1}$ Professor V.F. Voino-Yasenetsky Krasnoyarsk State Medical University, Krasnoyarsk, Russia \\ ${ }^{2}$ Clinical hospital "Russian Railways-Medicine", Krasnoyarsk, Russia
}

Received 27 November 2019, Revised 19 June 2020, Accepted 12 August 2020

(C) 2019, Pakhomova R.A., Karapetyan G.E., Kochetova L.V., Sindeeva L.V., Karelina N.A., Ratushniy N.A

(C) 2019, Russian Open Medical Journal

Abstract: Objective - to reveal the incidence of tubular breast deformity and to compare macromorphometric breast data with the constitution of women who need aesthetic breast correction.

Material and Methods - There was conducted macromorphometry of the mammary glands in 101 women using the Body Logic system, as well as anthropometry and somatotyping with indication of sthenic, ectomorph and endomorph body types.

Results - Among women with aesthetic problems of mammary glands, tubular breast deformity was revealed in $17.6 \%$ of sthenics, $23.5 \%$ of ectomorphs, and $58.8 \%$ of endomorphs. The Norwood Index, as an objective criterion of tubularity, had the largest value in endomorph women.

Conclusion - Endomorph women were more susceptible to the development of tubular breast deformity in comparison with women of other body types.

Keywords: mammary gland, morphometry, tubularity, somatotype.

Cite as Pakhomova R.A., Karapetyan G.E., Kochetova L.V., Sindeeva L.V., Karelina N.A., Ratushniy N.A. Morphometric parameters of mammary glands in women of different body types in the normal condition and in case of tubular breast deformity. Russian Open Medical Journal 2020; 9: e0311.

Correspondence to Lyudmila V. Sindeeva. Address: Partizan Zheleznyak Str. 1, Krasnoyarsk, 660020, Russia. Phone: +79135337057. E-mail: Isind@mail.ru.

\section{Introduction}

In contemporary mammology much attention is paid to the health and aesthetics of mammary glands [1-4]. High requirements of women to their appearance, including breast, necessitate constant improvement in plastic surgery technologies. Breast surgical procedures performed in the contemporary world can be called the evolutionary achievement of medical science. At the same time, aesthetic operations with the use of silicone implants sometimes lead to adverse medical consequences - these can be both clinical complications and patient's dissatisfaction with the result. Capsular contracture is one of the most frequent clinical complications of augmentation mammoplasty. According to the data from different authors, it occurs in about $74 \%$ of women. Furthermore, in $12 \%$ of women the formation of a dense capsule around the implant requires re-operation in the first 2 years given that this percentage increases with time and over the next 3 years it reaches $20 \%$. The prevention of the development of capsular contracture has been worrying plastic surgeons since the introduction of mammoplasty into practice. By now, there has been identified a sufficient number of reasons causing capsular contracture. However, there is no single treatment; neither criteria have been developed to predict the development of capsular contracture nor preventive measures [4-6]. There is an opinion that complications that develop after augmentation mammoplasty are more common in women with a tubular form of the breast [7]. In this regard, fundamental disciplines can help the surgeon. In particular, constitutional anatomy allows us to consider issues of breast surgery from individual perspective [8]. However, despite all the relevance of the clinical anatomy of mammary glands in terms of its practical application, studies that compare the morphometric characteristics, taking into account the constitution of the body, are not numerous.

In connection with the importance of the problem, there was set the objective of the research: to reveal the incidence of tubular breast deformity and to conduct a comparative analysis of the results of breast macromorphometry and the somatotype of women who need aesthetic breast correction.

\section{Material and Methods}

The research was carried out among 101 women of the first period of mature age (21-35) who applied to the clinic of plastic surgery for the possibility of surgical correction of mammary glands. The criterion for exclusion from the survey was the presence of childbirth in case history.

Breast macromorphometry was carried out using the Body Logic system, developed specifically for the company "Mentor", a manufacturer of silicone implants [9]. The following measurements were included into the research program: the 
distance from the jugular notch to the breast crease, from the jugular notch to the nipple, from the nipple to the breast crease, from the nipple to the breast crease under tension, the thickness of the skin-glandular fold in the upper poles of the mammary gland. The elasticity of the skin in the lower pole region was also evaluated by calculating the difference in the distance from the nipples to the breast crease with and without skin tension, which was calculated by the formula: $S=T-D$, where $S$ was the skin extensibility in the region of the lower pole of the breast, $\mathrm{T}$ was the distance from the nipples to the breast crease of the mammory gland with tension, $\mathrm{D}$ was the distance from the nipples to the breast crease without tension [9].

After measuring the diameter and degree of protrusion of the areola, the Norwood index (IN) was calculated using the following formula: IN = areola protrusion / areola diameter. On the basis of IN value, tubular breast deformity was either established or excluded. Tubular deformity was established in case of an index value from 0.41 to 0.66 [9].

Somatotype was determined by the Rees-Eysenk index according to the formula: Index=BLx100/(TTDx6), where BL was the body length $(\mathrm{cm})$, TTD was the transverse thoracic diameter $(\mathrm{cm})$. If the obtained indicator did not exceed 96, the constitutional type was regarded as pyknic (endomorph). With an index value ranging from 96 to 106, the somatotype was recognized as normosthenic. If the index value exceeded 106, such women were classified as asthenic (ectomorph) [10]. Body mass index (BMI) was also calculated.

In the statistical processing of the retrieved data, nonparametric methods for data analysis were used in MS Office Excel 2010, as well as SPSS Statistics 22.0. Central tendencies and dispersions of quantitative characteristics were evaluated by the median, the third and the first quartiles - Me (LQ, UQ). The significance of intergroup differences in quantitative characteristics was evaluated using the non-parametric MannWhitney $U$ test, qualitative - using $\chi 2$ criterion. Correlation analysis was also used.

There was examined the pair correlation dependence of each parameter with the calculation of the correlation coefficient $r$. The degree of correlation was estimated as follows: when the coefficient value was $r<0.3$, there was no relationship between the features, at $0.3<r<0.5$ - there was a weak degree of correlation, at $0.5<r<0.7-$ there were average correlation degrees and $r>0.7$ was regarded as a strong degree. A critical significance level was recognized as $p<0.05$.

\section{Results}

The examined women were divided into three groups according to their somatotypes: normosthenic (sthenic) somatotype was detected in $32.7 \%$ of women, asthenic (ectomorph) - in 33.7\%, and endomorph (pyknic) type - in 34.6\% of women. The median length of women's body was 164.0 (158.8, $167.2) \mathrm{cm}$, body weight $-62.8(59.4,64.7) \mathrm{kg}$. It should be noted that endomorphy (pyknic type) is not always associated with overweight; it can be connected with large size of the chest, defined in the frontal plane. Our research confirmed this concept. Among the examined women there were no registered persons with overweight and obesity. $80.2 \%$ of women had normal BMI values. $19.8 \%$ of women had weight deficit.

The use of individual typological approach during the initial examination of women revealed a number of significant features of the morphometric parameters of mammary glands, depending on the body type. In women of sthenic somatotype, the distance from the jugular notch to the breast crease was 24.7 (24.1, 25.2) $\mathrm{cm}$, which is significantly less than that of the representatives of asthenic somatotype $-25.5(23.6,25.7) \mathrm{cm}$ and more than that of the pyknic somatotype $-23.4(20.5,26.2) \mathrm{cm}$.

According to the distance from the jugular notch to the nipple, somatotypes were clearly ranged: the smallest distance was found in sthenics - $17.0(16.5,17.1) \mathrm{cm}$, the biggest one in endomorphs $18.3(17.9,18.6) \mathrm{cm}$, ectomorphs occupied a middle position between the sthenics and endomorphs by the value of this parameter - $17.5(17.3,17.6) \mathrm{cm}$. Also, women of pyknic type were characterized by minimal values of the distance from the nipple to the breast crease at rest and during tension in the absence of statistically significant differences in the indicated characteristics between the representatives of asthenic and sthenic somatotypes. The thickness of the skin-glandular folds in the upper poles of the breast and skin extensibility in the area of the lower pole of the gland revealed no typological features (Table 1).

Tubular breast deformity was detected in $33.6 \%$ of women who needed aesthetic correction. At the same time, a differentiated approach to this problem, taking into account the body type, made it possible to identify a number of specific features. Thus, the Norwood index for women of sthenic type was $0.31(0.24,0.36)$, which was not significantly different from asthenic $-0.27(0.24,0.36), p=0.158$. At the same time, women of pyknic type were characterized by its higher values $-0.44(0.24$, $0.57), p=0.023$.

The frequency of the tubular mammary gland, depending on the somatotype, is presented in Figure 1.

Table 1. Morphometric parameters of mammary glands depending on the somatotype

\begin{tabular}{|c|c|c|c|}
\hline Parameters & Normosthenic (1) & Asthenic (2) & Pyknic (3) \\
\hline \multirow{2}{*}{ The distance from the jugular notch to the breast crease, $\mathrm{cm}$} & $24.7(24.1,25.2)$ & $25.5(23.6,25.7)$ & $23.4(20.5,26.2]$ \\
\hline & \multicolumn{2}{|c|}{$\mathrm{p} 1-2=0.003, \mathrm{p} 2-3=0.012, \mathrm{p} 1-3=0.031$} & \\
\hline \multirow{2}{*}{ The distance from the jugular notch to the nipple, $\mathrm{cm}$} & $17.0(16,5,17,1)$ & $17.5(17,3,17,6)$ & $18.3(17,9,18,6$ \\
\hline & \multicolumn{2}{|c|}{$\mathrm{p} 1-2<0.001, \mathrm{p} 2-3<0.001, \mathrm{p} 1-3<0.001$} & \\
\hline \multirow{2}{*}{ The distance from the nipple to the breast crease, $\mathrm{cm}$} & $8.1(8.0,8.2)$ & $8.1(7.8,8.3)$ & $4.8(2.5,8.1]$ \\
\hline & \multicolumn{2}{|c|}{$\mathrm{p} 1-2=0.560, \mathrm{p} 2-3=0.013, \mathrm{p} 1-3=0.008$} & \\
\hline \multirow{2}{*}{ The distance from the nipple to the breast crease in tension, $\mathrm{cm}$} & $9.7(9.5,9.8)$ & $9.7(9.3,9.9)$ & $6.0(4.0,9.9]$ \\
\hline & \multicolumn{2}{|c|}{$\mathrm{p} 1-2=0.925, \mathrm{p} 2-3=0.048, \mathrm{p} 1-3=0.044$} & \\
\hline \multirow{2}{*}{$\begin{array}{l}\text { The thickness of the skin-glandular fold in the region of the upper pole of } \\
\text { the mammary gland, } \mathrm{cm}\end{array}$} & $2.8(2.7,3.1)$ & $2.5(2.1,3.0)$ & $3.2(2.3,3.4]$ \\
\hline & \multicolumn{2}{|c|}{$\mathrm{p} 1-2=0.065, \mathrm{p} 2-3=0.078, \mathrm{p} 1-3=0.089$} & \\
\hline \multirow{2}{*}{ The elasticity of the skin in the region of the lower pole of the gland, $\mathrm{cm}$} & $1.6(1.5,1.7)$ & $1.6(1.4,1.7)$ & $1.5(1.4,1.8]$ \\
\hline & \multicolumn{2}{|c|}{$\mathrm{p} 1-2=0.905, \mathrm{p} 2-3=0.765, \mathrm{p} 1-3=0.771$} & \\
\hline
\end{tabular}




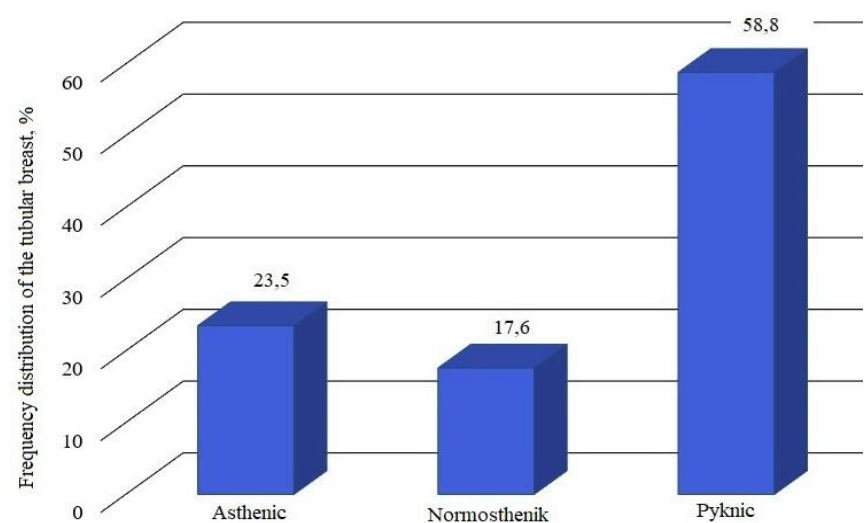

Figure 1. The frequency of the tubular mammary gland, depending on the somatotype.

It was adjusted that the aesthetic problems of women of pyknic somatotype were due to the presence of tubular breast deformity, which was registered in $58.8 \%$ of cases in our study. Among ectomorphs, the tubular mammary gland was found in $23.5 \%$ of cases, and in $17.6 \%$ of cases in sthenics.

The correlation of the tubular breast deformity with the morphometric parameters of the mammary gland and the somatotype was objectively confirmed by the results of the correlation analysis. There were established strong inverse correlations between the Norwood index and the distance from the jugular notch to the breast crease $(r=-0.865, p<0.001)$, the Norwood index and the distance from the nipples to the breast crease in a free state $(r=-0.879, p=0.002)$ and under tension ( $r=-$ $0.885, p=0.004)$. Also, this index correlated with the thickness of the skin-glandular fold in the region of the upper pole of the mammary gland $(r=0.716, p<0.001)$ and the elasticity of the skin in the region of the lower pole of the gland $(r=-0.674, p<0.001)$.

There were found direct correlations of the average force between the Norwood index and BMI (body mass index) ( $r=0.523$, $\mathrm{p}=0.013$ ). In other words, when the BMI was higher, there was a greater risk of the formation of tubular breast deformity. All correlations were statistically significant $(p<0.05)$.

\section{Discussion}

The tubular form of the mammary gland is a case when the breast has the shape of a high cone on a narrow base, with a wide and protruding areola. From 8 to $15 \%$ of patients in aesthetic surgery clinics have signs of a tubular breast [11]. This deformation of the mammary gland causes the greatest psychological discomfort in patients and is one of the most difficult tasks for plastic surgeons. Today, there is no universally accepted standard of surgical tactics for patients with tubular deformity changes of mammary glands, since the volume of glandular tissue deficiency varies depending on the particular clinical case [12] The choice of the most appropriate technique to achieve optimal results of surgical correction is exclusively the prerogative of the operating plastic surgeon $[13,14]$.

Anatomical justification is obligatory in determining the tactics of corrective surgery of mammary glands. Anthropological approach during mammoplasty had already been raised earlier. In the research of V.N. Kasanov et al. [15] special attention was paid to the influence of the ethnic component on the formation of various forms of mammary glands, it was recommended to consider it while selecting an implant and it was important for the development of measures to prevent adverse postoperative complications. At the same time in the available literature there was practically no information about the constitutional features of the morphometric parameters of mammary glands in the formation of their anatomical features requiring aesthetic correction. In the present study, there had been made an attempt to compare the data of breast morphometry with the body type of women, which we regard as a scientific novelty.

\section{Conclusion}

According to the results of the study, the following conclusion can be made: women of pyknic somatotype were more susceptible to the development of tubular breast deformity in comparison with women of other body types.

\section{Ethical approval}

All procedures conducted in human studies were consistent with the ethical standards of the national research committee and the Declaration of Helsinki, 1964. The study was approved by the local ethics committee of Prof. V.F. Voino-Yasenetsky Krasnoyarsk State Medical University (Krasnoyarsk, Russia).

\section{Conflict of interest}

The authors declare no conflict of interest.

\section{References}

1. Golovatch VA, Borovikov AM. Double-bubble deformity. Tubularity is not principal. Plasticheskaya hirurgiya i kosmetologiya 2013; (4): 523 536. Russian. https://www.elibrary.ru/item.asp?id=21116230.

2. Ivanova LN, Tananakina TP, Korobkova EA, Karpushin DI, Lutsenko AI Connection between aesthetic health of female students and bad habits. University Clinic 2017; (4-2(25)): 53-56. Russian. https://www.elibrary.ru/item.asp?id=30744605.

3. Kazanov VN, Garmayeva DK, Khayrullin RM. Morphometry of the breast in the middle age women in Republic Sakha (Yakutia) Znanie 2015; $\quad$ (12-2(29)): 99-103. https://www.elibrary.ru/item.asp?id=25463191.

4. Svanadze SN. Modern approaches to standardization of interventions in mammoplasty. Health care Standardization Problems 2016; (7-8): 57-60. https://www.elibrary.ru/item.asp?id=26562026.

5. Fagell D, Berggren E, Tapila E. Capsular contracture around line-filled fine textured and smooth mammary implants: a prospective year follow-up. Plast Reconstr Surg 2001; 108(7): 2108-2112. https://doi.org/10.1097/00006534-200112000-00046.

6. Karapetyan GE, Ratushny NA, Pakhomova RA, Kochetova LV, Capsular contracture: causes, prevention. Surgical practice 2017; (2): 42-46. https://www.elibrary.ru/item.asp?id=32607150.

7. Ribeiro L, Accorsi AJ, Argencio V. Tuberous breast: a periareolar approach. Aesthet Surg J 2005; 25(4): 398-402. https://doi.org/10.1016/j.asj.2005.05.013.

8. Khodjamurodova DA, Saidov MS, Khodjamuradov GM. Application of silicone implants in mammoplasty (literature survey). I.P. Pavlov Russian Medical Biological Herald 2018; 26(1): 133-149. Russian. https://doi.org/10.23888/PAVLOVJ2018261133-149.

9. Hammond DC. Atlas of aesthetic breast surgery. Saunders Elsevier 2009: 11-38. https://www.elsevier.com/books/atlas-of-aestheticbreast-surgery/hammond/978-1-4160-3184-0.

10. Rees W, Eysenck $\mathrm{H}$. A factorial study of some morphological aspects of human constitution. J Mental Sci 1945; 91(386): 8-21. https://hanseysenck.com/wp- 
content/uploads/2019/12/1945 rees eysenck -

factorial_study_of_some_morphological_and_psychological_aspects. pdf.

11. DeLuca-Pytell DM, Piazza RC, Holding JC, Snyder N, Hunsicker LM, Phillips LG. The incidence of tuberous breast deformity in asymmetric and symmetric mammaplasty patients. Plas Reconstr Surg 2005; 116(7): 1894-1899. https://doi.org/10.1097/01.prs.0000189206.94466.a9.

12. Nahabedian MY. Breast deformities and mastopexy. Plast Reconstr
Surg
2011
127(4):
91e-102e.

https://doi.org/10.1097/prs.0b013e31820a7fa7.

13. Delay E, Sinna R, Ho Quoc C. Tuberous breast correction by fat grafting. Aesthet Surg J 2013; 33(4): 522-528. https://doi.org/10.1177/1090820×13480641.

14. Illouz YG, Sterodimas A. Autologous fat transplantation to the breast: a personal technique with 25 years of experience. Aesthetic Plast Surg 2009; 33(5): 706-715. https://doi.org/10.1007/s00266-009-9377-1.

15. Kazanov VN, Garmaeva DK, Khayrullin RM, Filippova EN, Frequency of the occurrence of the various forms of mammary glands of women in Sakha Republic (Yakutia). Journal of Anatomy and Histopathology 2016; 5(3): 27-30. https://www.elibrary.ru/item.asp?id=26730822.

\section{Authors:}

Regina A. Pakhomova - MD, DSc, Assistant of the Department of General surgery named after prof. M.I. Gulman, Prof. V.F. Voino-Yasenetsky Krasnoyarsk State Medical University, Krasnoyarsk, Russia. https://orcid.org/0000-0002-3681-4685.

Georgy E. Karapetyan - MD, DSc, Associate Professor, Professor of the Department of General surgery named after prof. M.I. Gulman, Prof. V.F. Voino-Yasenetsky Krasnoyarsk State Medical University, Krasnoyarsk, Russia. https://orcid.org/0000-0002-1216-2029.

Lyudmila V. Kochetova - MD, PhD, Associate Professor, Professor of the Department of General surgery named after prof. M.I. Gulman, Prof. V.F. Voino-Yasenetsky Krasnoyarsk State Medical University, Krasnoyarsk, Russia. https://orcid.org/0000-0001-5784-7067.

Lyudmila V. Sindeeva - MD, DSc, Associate Professor, Professor of the Department of Anatomy and Human Histology, Prof. V.F. Voino-Yasenetsky Krasnoyarsk State Medical University, Krasnoyarsk, Russia. https://orcid.org/0000-0003-0469-9552.

Natalya A. Karelina - Senior Lecturer of the Department of Latin and Foreign Languages, Prof. V.F. Voino-Yasenetsky Krasnoyarsk State Medical University, Krasnoyarsk, Russia. https://orcid.org/0000-0001-9627-3326.

Nikolay A. Ratushny - MD, Plastic surgeon, Clinical hospital "Russian Railways-Medicine", Krasnoyarsk, Russia. https://orcid.org/0000-00022050-3866. 